University of Nebraska - Lincoln

DigitalCommons@University of Nebraska - Lincoln

\title{
Novel Algorithms for Remote Estimation of Vegetation Fraction
}

Anatoly A. Gitelson

University of Nebraska - Lincoln, agitelson2@unl.edu

Yoram J. Kaufman

NASA Goddard Space Flight Center, Greenbelt, MD

Robert Stark

Ben-Gurion University of the Negev, Beer-Sheva, Israel

Don Rundquist

University of Nebraska - Lincoln, drundquist1@unl.edu

Follow this and additional works at: https://digitalcommons.unl.edu/natrespapers

Part of the Natural Resources and Conservation Commons

Gitelson, Anatoly A.; Kaufman, Yoram J.; Stark, Robert; and Rundquist, Don, "Novel Algorithms for Remote Estimation of Vegetation Fraction" (2002). Papers in Natural Resources. 149.

https://digitalcommons.unl.edu/natrespapers/149

This Article is brought to you for free and open access by the Natural Resources, School of at DigitalCommons@University of Nebraska - Lincoln. It has been accepted for inclusion in Papers in Natural Resources by an authorized administrator of DigitalCommons@University of Nebraska - Lincoln. 


\title{
Novel algorithms for remote estimation of vegetation fraction
}

\author{
Anatoly A. Gitelson ${ }^{\mathrm{a}, \mathrm{c}, *}$, Yoram J. Kaufman ${ }^{\mathrm{b}}$, Robert $\operatorname{Stark}^{\mathrm{c}}$, Don Rundquist ${ }^{\mathrm{a}}$ \\ ${ }^{a}$ Center for Advanced Land Management Information Technologies, School of Natural Resource Sciences, \\ University of Nebraska-Lincoln, Lincoln, NE 68588-0517, USA \\ ${ }^{\mathrm{b}}$ NASA Goddard Space Flight Center, Greenbelt, MD 20771, USA \\ ${ }^{\mathrm{c}}$ Department of Geological and Environmental Sciences, Ben-Gurion University of the Negev, Beer-Sheva, Israel
}

Received 28 July 2000; received in revised form 7 June 2001; accepted 25 June 2001

\begin{abstract}
Spectral properties of a wheat canopy with vegetation fraction (VF) from $0 \%$ to $100 \%$ in visible and near-infrared (NIR) ranges of the spectrum were studied in order to devise a technique for remote estimation of VF. When VF was $<60 \%$, from emergence till middle of the elongation stage, four distinct, and quite independent, spectral bands of reflectance existed in the visible range of the spectrum: 400 to $500 \mathrm{~nm}, 530$ to $600 \mathrm{~nm}$, near $670 \mathrm{~nm}$, and around $700 \mathrm{~nm}$. When VF was between $60 \%$ and 100\%, reflectance in the NIR leveled off or even decreases with an increase of VF. The decreased reflectance in the NIR, occurring at or near the midseason, can be a limiting factor in the use of that spectral region for $\mathrm{VF}$ estimation. It was found that for $\mathrm{VF}>60 \%$, the information content of reflectance spectra in visible range can be expressed by only two independent pairs of spectral bands: (1) the blue from 400 to $500 \mathrm{~nm}$ and the red near $670 \mathrm{~nm}$; (2) the green around $550 \mathrm{~nm}$ and the red edge region near $700 \mathrm{~nm}$. We propose using only the visible range of the spectrum to quantitatively estimate VF. The green (as well as a 700-nm band) and the red (near $670 \mathrm{~nm}$ ) reflectances were used in developing new indices, which were linearly proportional to wheat VF ranging from $0 \%$ to $100 \%$. The Atmospherically Resistant Vegetation Index (ARVI) concept was used to correct indices for atmospheric effects. Visible Atmospherically Resistant Index in the form VARI $=\left(R_{\text {green }}-R_{\text {red }}\right) /\left(R_{\text {green }}+R_{\text {red }}-R_{\text {blue }}\right)$ was found to be minimally sensitive to atmospheric effects allowing estimation of VF with an error of $<10 \%$ in a wide range of atmospheric optical thickness. Validation of the newly suggested technique was carried out using wheat independent data sets and reflectance data obtained for cornfields in Nebraska. Predicted green VF was compared with retrieved from digital images. Despite the fact that the reflectance contrast among the visible channels is much smaller than between the visible and NIR, the sensitivity of suggested indices to moderate to high values of VF is much higher than for the Normalized Difference Vegetation Index (NDVI), and the error in VF prediction did not exceed 10\%. Suggested indices will complement the widely used NDVI, ARVI, Soil Adjusted Vegetation Index (SAVI) and others, which are based on the red and the NIR bands in VF estimation, and also Green Atmospherically Resistant Index (GARI), which is based on the green and the NIR bands.
\end{abstract}

\section{Introduction}

Spectral vegetation indices are widely used for monitoring, analyzing, and mapping temporal and spatial variations in vegetation structure as well as certain biophysical parameters. Such indices enable assessment and monitoring of changes in canopy biophysical properties such as vegetation fraction (VF), leaf area index (LAI), fraction of absorbed photosynthetically active radiation, and net primary produc-

* Corresponding author. Center for Advanced Land Management Information Technologies, School of Natural Resource Sciences, University of Nebraska-Lincoln, Lincoln, NE 68588-0517, USA. Tel.: +1-402-4728386; fax: +1-402-472-4608.

E-mail address: gitelson@calmit.unl.edu (A.A. Gitelson). tion (e.g., Asrar, Fuchs, Kanemasu, \& Hatfield, 1984; Holben, 1986; Myneni, Hall, Sellers,\& Marshak, 1995; Myneni, Keeling, Tucker, Asrar, \& Nemani, 1997; Myneni, Nemani, \& Running, 1997; Sellers, 1985, 1987; Tucker, 1979; Tucker, Fung, Keeling, \& Gammon, 1986).

Considerable effort has been expended in improving the well-known Normalized Difference Vegetation Index (NDVI) (Rouse, Haas, Schell, \& Deering, 1974) and in developing new indices to compensate both for the atmosphere (e.g., Kaufman, 1989; Kaufman \& Tanre, 1992), and soil background (e.g., Baret, Guyot, \& Major, 1989; Baret, Jacquemoud, \& Hanocq, 1993; Huete, 1988). Gobron, Pinty, Verstraete, and Govaerts (1999) suggested the MERIS Global Vegetation Index to identify and monitor the presence of live vegetation when using data from MERIS 
instrument. Taking advantage of the presence of a blue channel, they isolated the properties of the vegetation layer from the spectral and directional perturbations of both the atmosphere and other geophysical media. An optimization scheme was applied to define the best possible "spectral angular index," which simultaneously minimizes atmospheric and geometric effects.

Most vegetation indices combine information contained in two spectral bands, the red and near-infrared (NIR). The indices have limitations, some of which are due to choices of band location and width. Examples include the minimal sensitivity of the NDVI to moderate to high chlorophyll content, VF and LAI (Buschmann \& Nagel, 1993; Gitelson \& Merzlyak, 1994a, 1994b; Myneni, Nemani, et al., 1997). In agronomic crops, NIR reflectance levels off or even decreases with an increase of VF (see, for example, Kanemasu, 1974). With regard to the latter phenomenon, a search of the literature has led to three explanations:

(1) NIR reflectance decreases as a result of a change in leaf orientation, from predominantly horizontal to predominantly vertical, at a certain stage in the growth cycle (Colwell, 1974; Jackson \& Ezra, 1985; Suits, 1972). Jackson and Pinter (1986) found that the architecture of the plant canopy determines possible reflection directions for incident radiation. For example, the vertical arrangement of leaves in an erectophile canopy generally scatters more radiation into lower layers than the more horizontal arrangement of a planophile canopy. Thus, for erectophile vegetation, more radiation is trapped within the canopy, increasing the ability of the plant to absorb light, thereby decreasing the NIR reflectance.

(2) At a certain phenological stage of wheat development, called "booting," the lower leaves of a plant begin to turn brown, due to a loss of chlorophyll. The result is a decrease in the number of actively reflecting leaf layers, with a consequent decrease in NIR reflectance (Leamer, Noriega, \& Gerbermann, 1980). Leamer, Noriega, and Wiegand (1978) reported that the NIR reflectance of wheat decreased by nearly $20 \%$ when VF increased from $55 \%$ to $80 \%$. Tucker, Holben, Elgin, and McMurtrey (1981) showed the decrease of NIR reflectance around the booting stage when VF was over $60 \%$.

(3) The contribution of soil reflectance to total canopy reflectance in the NIR is significant (e.g., Allen \& Richardson, 1968). It is well known that an increase in soil moisture causes a decrease in NIR reflectance of that soil; thus, an increase in soil moisture may lead to a decrease in the NIR reflectance of a canopy (Daughtry, Bauer, Crecelius, \& Hixson, 1980; Fernandez, Vidal, Simon, \& Sole-Sugranes, 1994; Huete, Jackson, \& Post, 1985; Jackson, Slater, \& Pinter, 1983; Kanemasu, 1974).

An additional point to emphasize is that NIR reflectance is no doubt species specific due to its dependence on factors such canopy architecture, cell structure, leaf inclination, etc. In contrast, reflectance in the visible range is less species specific because it is governed mainly by pigment content and composition. Relationships of reflectance with chlorophyll content at specific wavelengths remain quantitatively the same in leaves of different and unrelated plant species (Aoki, Yabuki, Totsuka, \& Nishida, 1986; Gitelson \& Merzlyak, 1997).

The decreased reflectance in the NIR, occurring at or near the midseason of a growing crop, can be a limiting factor in the use of that spectral region for estimation of VF. Therefore, we propose using only the visible range of the spectrum to quantitatively estimate $\mathrm{VF}$, and we are interested in applying the algorithms to new satellite technologies including the high spectral and radiometric resolution achieved in the recently launched Sea-Viewing Wide Fieldof-View Sensor (SeaWiFS), Moderate-Resolution Imaging Spectrometer (MODIS), Advanced Spaceborne Thermal Emission and Reflection Radiometer (ASTER), Multiangle Imaging Spectro-Radiometer (MISR), and near future space systems such as Hyperion and Medium-Resolution Imaging Spectrometer (MERIS). In the current study, MODIS and MERIS data were simulated.

The first step in our research was to evaluate the information content inherent in reflectance spectra in the range 400-700 $\mathrm{nm}$. Next, we examined spectral indices based only on bands in the visible spectrum: the green (near $550 \mathrm{~nm}$ ) or red edge near $700 \mathrm{~nm}$, and the red (near $670 \mathrm{~nm}$ ), as means of measuring VF. Finally, developed indices were validated by independent data sets taken above wheat and corn fields.

\section{Methods}

Data were collected during two growing seasons in wheat fields near the city of Beer-Sheva, Israel $\left(31^{\circ} 13^{\prime} \mathrm{N}\right.$, $34^{\circ} 48^{\prime} \mathrm{W}$ ), located on the northern edge of the Negev Desert. The wheat was irrigated on a regular basis by water effluent from a nearby reservoir, using sprinklers installed in straight parallel lines. In the first year, experiments were conducted from the middle of December 1997 till the middle of May 1998, and consisted four species of wheat-Ariel, Ayalon, Beit-Hashita, and Yaniv. In the second year, the 1998-1999 growing season, one species of wheat, Ayalon, was investigated. The difference among the species is mainly in their purpose for growing seeds or fodder. There was also a difference in their physical characteristics, such as plant height and density of canopy.

The data were collected over the course of the growing season from sowing until harvesting, at 1-2-week intervals. VF ranged from $0 \%$ to $100 \%$, while LAI reached a maximum of 12.

Reflectance spectra were acquired within each field at a few randomly selected locations. Reflectance spectra were measured above the canopy using a Licor LI-1800 high spectral resolution spectroradiometer in the range $400-1100 \mathrm{~nm}$ with a spectral resolution of $2 \mathrm{~nm}$. To measure upwelling radiance of the object $\left(L_{\text {object }}\right)$, an LI-1800 
was attached to a telescope with a field of view (FOV) of $15^{\circ}$, which was positioned above the canopy at a height of about $2 \mathrm{~m}$. Measurements of upwelling radiance were repeated at least five times at each sampling station and the average value was used in the analysis. Each reading took approximately $25 \mathrm{~s}$. Upwelling radiance of a $\mathrm{BaSO}_{4}$ panel $\left(L_{\mathrm{ref}}\right)$ was measured twice at each sampling station, before and just after measurements of wheat reflectance, and used as reference. A microcomputer initiated spectroradiometer scanning and stored the data. Then, in the laboratory, data were downloaded to the computer and the upwelling radiance from each vegetation-target scan was normalized to the appropriate upwelling radiance spectrum acquired over the reference panel.

Radiometric data were collected close to solar noon (between 11 a.m. and 1 p.m.); changes in solar zenith were minimal. Each measurement campaign (11 total in $1997 / 1998$ season and 13 total in 1998/1999 season) took about an hour. Over the course of the growing season, solar elevation for the study site varied significantly (from $31.8^{\circ}$ to $53^{\circ}$ ). Since the directional response of the reference panel is non-lambertian, the correction of anisotropic reflectance from the calibration target was made in accord with (Jackson, Clarke, \& Moran, 1992).

To estimate green VF, a Kodak DC-40 digital camera was used. Green VF is the vertical projection of the green vegetation (including leaves, stems, and branches) to the ground surface expressed as percent of the reference area (e.g., Purevdorj, Tateishi, Ishiyama, \& Honda, 1998). White, Asner, Nemani, Privette, and Running (2000), conducting intercomparison of VF estimation by various techniques, recommended digital camera as the easiest and the most reliable technique for validation of remote sensing information.

Digital images were acquired at each plot at the same height as the radiometric scan and the images were imported into ERDAS Imagine (ver. 8.3.1) for processing. The area (size) and location of the LI-1800 spectroradiometer FOV in each image was determined and a model was designed to exclude data outside the FOV. For green VF estimation we used approach suggested by Woebbecke, Meyer, Von Bargen, and Mortensen (1995), employing green and red brightness to distinguish green plants against a natural background of soils and residues. Model was developed to separate nonvegetation pixels from vegetation pixels, allowed for easy discrimination between soil (larger red/ green ratio) and vegetation (smaller red/green ratio). Visual image analysis showed that (1) there was no misclassification of dead vegetation as green material as it took place when NIR and red information was used (White et al., 2000); (2) shadowed soil was correctly classified as soil; and (3) vegetation in deep shadow was classified as soil, leading to a possible underestimation of VF. However, due to favorable illumination angles, misclassification of vegetation and soil was minimal.

An algorithm validation procedure was used to test the robustness of the models across years and wheat species.
The combined data base (reflectance spectra and VF, collected from December 1997 till the middle of May 1999) was separated into model development and model testing data sets. For the model development dataset, data collected in the 1998-1999 growing season for Ayalon wheat were used. Model validation was attempted using data collected in the 1997-1998 growing season for four wheat species Ariel, Ayalon, Beit-Hashita, and Yaniv. Predicted VF were calculated using reflectance from the validation data set (blue: $459-479 \mathrm{~nm}$, green: $546-556 \mathrm{~nm}$, and red 620-670 nm channels of MODIS, and also red edge channel of MERIS: $700-710 \mathrm{~nm}$ ) with coefficients generated by regression calculated for the model development data set. The standard errors of VF prediction were estimated comparing VF predicted and retrieved from digital images.

Validation of the suggested technique was also carried out using reflectance data obtained for cornfields in Nebraska. Data were collected in 1998 (two data sets) and in 1999. The study area was the University of Nebraska Agricultural Research and Development Center, located near Mead, Nebraska. The specific study site was a oneacre field of corn planted in a randomized design consisting of 16 plots. Each plot measured $11.4 \times 12.2 \mathrm{~m}$ or approximately $135 \mathrm{~m}^{2}$. VF ranged from $0 \%$ to $88 \%$ in 1998 with a maximum of $95 \%$ in 1999. LAI reached 2.5 in 1998 and 3.4 in 1999.

Hyperspectral data were collected at close-range using a Spectron Engineering SE-590 portable spectroradiometer. The system detects and records spectral data in 252 usable bands with a spectral range from 365 to $1126 \mathrm{~nm}$. Average wavelength spacing between midpoints of adjacent bands is about $3 \mathrm{~nm}$. The sensor was configured to acquire eight individual radiance measurements, which were internally averaged and stored as a single data file. The controller is connected to a portable computer, which initiates the scanning procedure, graphically displays the reflectance values of the target, and stores the reflectance data. The sensor was positioned at a height of $5.8 \mathrm{~m}$ above the canopy and pointed due south to reduce shadowing. Data were collected close to solar noon (between 11 a.m. and 3 p.m.) when changes in solar zenith are minimal. The $15^{\circ}$ optic resulted in an FOV of $150 \mathrm{~cm}$ (diameter) at the top of the canopy. The sensor head was then positioned over six different sample locations within each plot and radiant flux was measured. A white Spectralon (Labsphere, North Sutton, $\mathrm{NH})$ reflectance standard was used to calibrate the spectroradiometer to the total incoming radiant flux. Upwelling radiance of the reference panel was measured twice in each plot before and after measurements of corn reflectance. All canopy radiance data were imported into Microsoft's Excel Spreadsheet software and the bidirectional reflectance factor was calculated as: $R_{\lambda \text { corn }}=\left(L_{\lambda \text { corn }}\left[\mu \mathrm{W} \mathrm{cm}{ }^{-2} \mathrm{sr}^{-1} \mathrm{~nm}^{-1}\right]\right) /$ $\left(L_{\lambda \text { panel }}\left[\mu \mathrm{W} \mathrm{cm}{ }^{-2} \mathrm{sr}^{-1} \mathrm{~cm}^{-1}\right]\right) 100$, where $L_{\lambda \text { corn }}$ is measured radiance for corn per wavelength, $\lambda, L_{\lambda \text { panel }}$ is measured radiance for the calibration panel per wavelength, $\lambda$, $R_{\lambda \text { corn }}$ is canopy reflectance (in \%). 
Spectral data were collected at regular intervals (every 3 weeks) throughout the season. Atmospheric conditions dictated whether or not data were actually collected on the scheduled dates and as a result, corn spectra were eventually collected at four stages of development. The reflectance values from the six sample locations within each plot were averaged, resulting in a single reflectance value, per wavelength, for each plot.

Digital camera images were acquired using a Kodak DC-40 system. The camera, mounted adjacent to the SE-590, provided above-canopy images from the view of the spectroradiometer. A digital image was acquired over each of the 16 plots concurrent with spectral data collection of the corn canopy. The digital camera images were imported into ERDAS Imagine (ver. 8.3.1) for processing. The area and location of the SE-590 FOV in each image was determined and a model was designed to exclude data outside the $152.5-\mathrm{cm}$ diameter of the FOV. The images were used to determine green VF as described above.

\section{Results and discussion}

\subsection{Information content of reflectance spectra}

Wheat reflectance in the visible spectrum decreased in an orderly fashion throughout the growing season, from plant

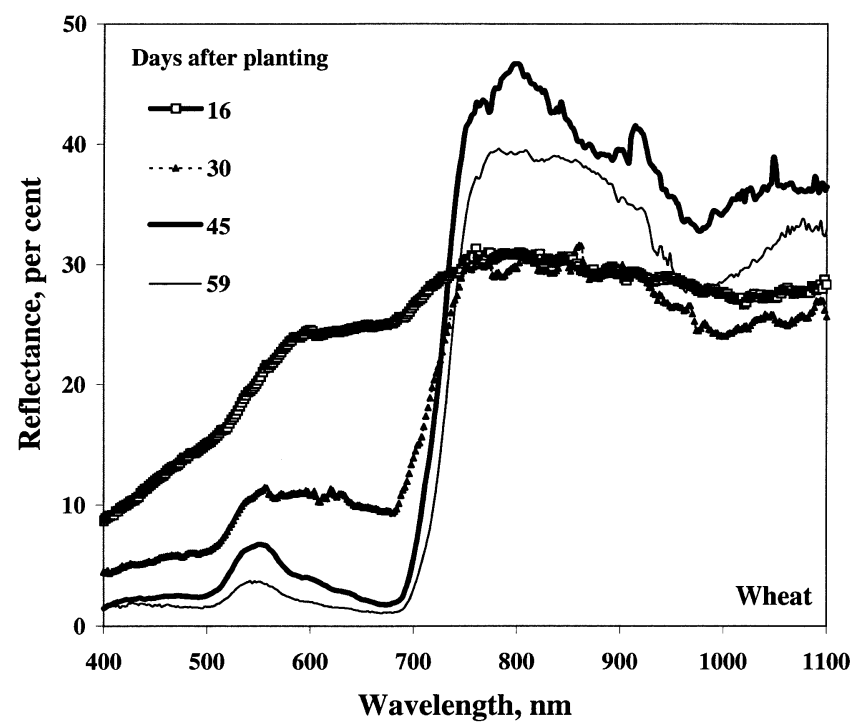

Fig. 1. Reflectance spectra of wheat measured during the course of a growing period in Israel. The spectral profiles represent an average of data taken over at least 11 sample locations. The range of VF was as follows: 16 th day after planting: $<10 \%$; 30th day after planting: $20-40 \%$; 45 th: $60-80 \%$; and 59th: $85-100 \%$. Reflectance in the visible spectrum decreased in an orderly fashion from emergence to heading. This decrease was most pronounced in the green and red ranges $(550-710 \mathrm{~nm})$ and least pronounced in the blue $(400-500 \mathrm{~nm})$. Beyond $750 \mathrm{~nm}$, reflectance ranged from $30 \%$ (elongation stage) to nearly $50 \%(\mathrm{VF}>70 \%$ ). During the last stage of wheat growth, NIR reflectance decreased from almost $50 \%$ to nearly $35 \%$ despite a continued increase in canopy density and vegetation cover. emergence to heading (Fig. 1). This decrease was most pronounced in the green and red ranges $(550-710 \mathrm{~nm})$ and least pronounced in the blue $(400-500 \mathrm{~nm})$. Beyond $750 \mathrm{~nm}$, reflectance ranged from about $20 \%$ (bare soil, not shown), through $30 \%$ at the elongation stage of wheat, and reached nearly $50 \%$ by day 52 after seeding (in the heading stage). During the last stage of wheat growth (59 day after seeding and later), NIR reflectance leveled off and even decreased from almost $50 \%$ to nearly $36 \%$, whereas VF and canopy density increased. During the course of the growing period, when the VF ranged from $60 \%$ to $100 \%$ (in the middle of the elongation stage and during the heading stage), canopy absorption in the NIR range $\left(R_{\mathrm{NIR}}\right)$ increased from about $17 \%$ to about $55 \%$ and transmittance decreased from $35.7 \%$ to $13.3 \%$ (Stark \& Gitelson, 1999, 2000). Such behavior of reflectance, absorption and transmittance in the NIR range was consistently observed in wheat canopies over two growing seasons.

Fig. 2A summarizes the relationships between VF and reflectance in blue $(470-490 \mathrm{~nm})$, green $(545-565 \mathrm{~nm})$, red $(660-680 \mathrm{~nm})$, and NIR $(841-876 \mathrm{~nm})$ for the Israeli wheat. When VF increased from 0 to $50 \%$, the reflectance in the red range $\left(R_{\text {red }}\right)$ decreased steeply, while the $R_{\mathrm{NIR}}$ increased. These characteristic spectral responses result in high sensitivity of the NDVI to $\mathrm{VF}<50 \%$ (Fig. 2B). The rate of change in both $R_{\text {red }}$ and $R_{\mathrm{NIR}}$ decreased when VF exceeded $50 \%$; they became virtually invariant to VF's between $60 \%$ and $100 \%$. The NDVI was nonsensitive to moderate to high VF\% (Fig. 2B).

For VF between $0 \%$ and about $50 \%$, both the red and the blue $\left(R_{\text {blue }}\right)$ reflectances decreased; the slope of decrease for the $R_{\text {red }}$ is much steeper than that for the $R_{\text {blue }}$. When $\mathrm{VF}=60 \%$, the $R_{\mathrm{blue}}$ and $R_{\text {red }}$ reached a mere $2.5-3 \%$ and then leveled off at an extremely low level (not higher than $2 \%$ ). Behavior of the $R_{\text {green }}$ was quite distinctive. It decreased with increase of VF remaining, nevertheless, almost equally sensitive to VF ranging from $0 \%$ to $100 \%$. When $\mathrm{VF}<60 \%$, the slope of the $R_{\text {green }}$ vs. VF curve is three times lower than that of $R_{\text {red }}$. Thus, early in the growing season, the red reflectance was more sensitive to VF than the green. But, when VF reached $60 \%$, the $R_{\text {red }}$ was noticeably less sensitive to VF; the sensitivity of the $R_{\text {red }}$ to VF was at least three times lower than of the $R_{\text {green }}$.

When VF increased from $60 \%$ to $100 \%, R_{670}$ change synchronously with $R_{490}$, and $R_{550}$ with $R_{700}$, thus, reflectances $R_{550}$ and $R_{700}$ as well as $R_{490}$ and $R_{670}$ were very closely correlated (Fig. 3). The information content of wheat reflectance spectra became lower; reflectance in the blue and the red ranges provide almost the same information. Thus, for $\mathrm{VF}>60 \%$ in the visible spectrum we have, in reality, only two independent spectral bands: (1) either near $490 \mathrm{~nm}$ (or around $670 \mathrm{~nm}$ ); and (2) either around $550 \mathrm{~nm}$ or near $700 \mathrm{~nm}$.

When wheat VF reached $60 \%$, spectral features of canopy reflectance closely resemble those of leaves. At leaf level, the relationship $R_{490}$ and $R_{670}$ vs. chlorophyll levels off even for slightly green leaves when total chlorophyll 

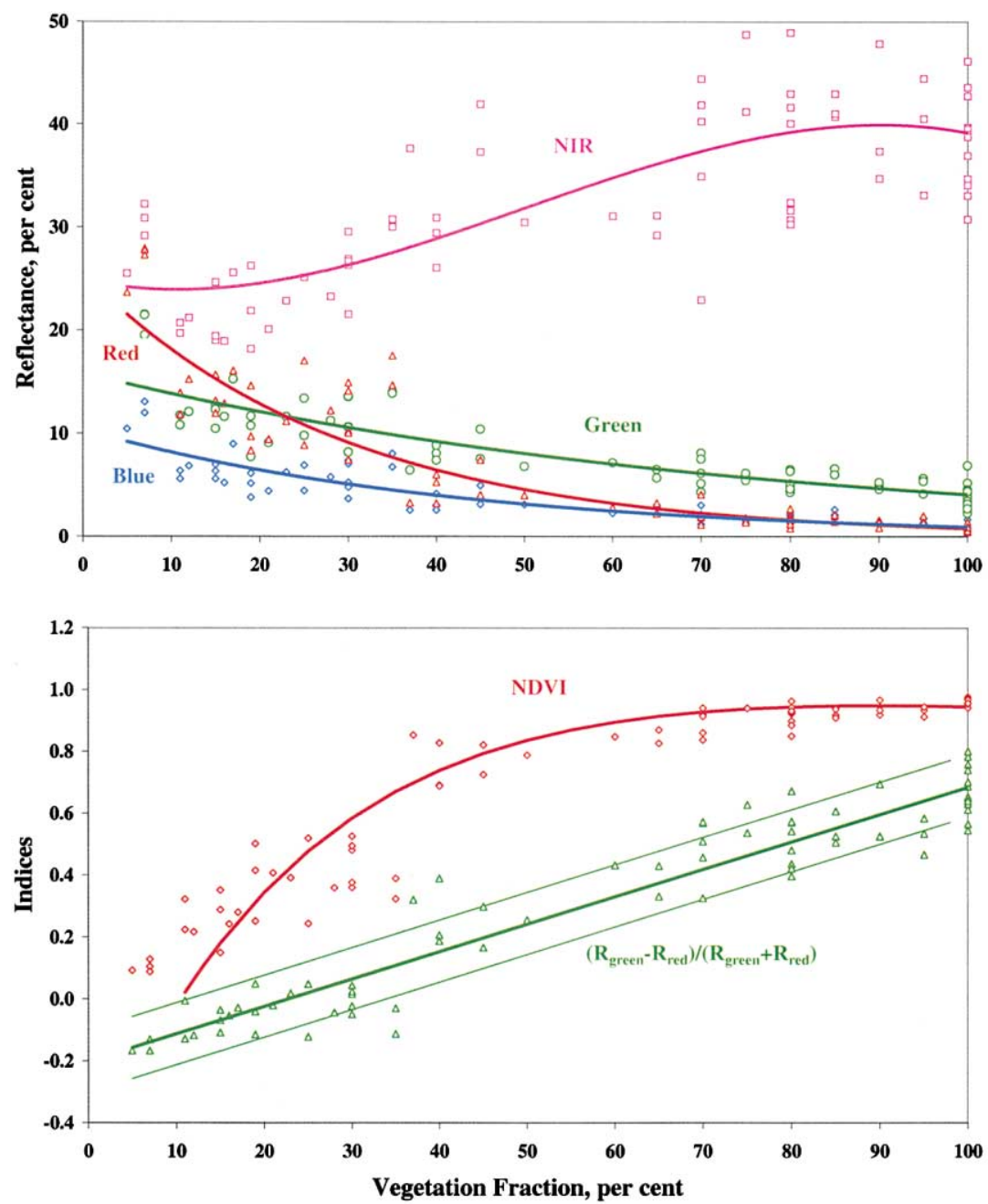

Fig. 2. (A) The blue $(470-490 \mathrm{~nm})$, green $(545-565 \mathrm{~nm})$, red $(660-680 \mathrm{~nm})$, and NIR $(841-876 \mathrm{~nm})$ reflectance versus VF in Israeli wheat. Solid lines are best-fit functions. When VF was between $0 \%$ and $50 \%$, the slope of decrease for $R_{\text {blue }}$ and $R_{\text {red }}$ was much steeper than for $R_{\text {green }}$. Early in the growing season, $R_{\text {red }}$ was more sensitive to VF than $R_{\text {green }}$. When VF reached $60 \%$, the $R_{\text {blue }}$ and $R_{\text {red }}$ dropped to very small values $(<3 \%)$. The behavior of $R_{\text {green }}$ was quite distinctive; the sensitivity of $R_{\text {green }}$ to VF changed relatively little with changing VF. At VF $>60 \%$, the sensitivity of $R_{\text {red }}$ to VF was at least three times lower than $R_{\text {green }}$. NIR reflectance increased with an increase in VF from $0 \%$ to $40 \%$, leveled off when VF reached about $50 \%$, and even decreased when wheat approached a VF of $80-90 \%$. (B) NDVI and index $\left(R_{\text {green }}-R_{\text {red }}\right) /\left(R_{\text {green }}+R_{\text {red }}\right)$ plotted versus VF. Solid lines are best-fit functions. Thin lines show root-mean square deviation of sample points from the linear relationship index $\left(R_{\text {green }}-R_{\text {red }}\right) /\left(R_{\text {green }}+R_{\text {red }}\right)$ versus VF. An important point here is that NDVI appears to be insensitive to $\mathrm{VF}$ change when $\mathrm{VF}>60 \%$.

content reached $100-150 \mathrm{mg} / \mathrm{m}^{2}$ (e.g., Buschmann \& Nagel, 1993; Gitelson \& Merzlyak, 1994a, 1996). In the wheat canopy, the relationships $R_{490}$ and $R_{670}$ vs. VF leveled off when VF reached $60 \%$ (Fig. 2A). In leaves, strong covariance exists between $R_{490}$ and $R_{670}$, as well as between $R_{550}$ and $R_{700}$. In the wheat canopy with $\mathrm{VF}>60 \%$, we have found the same behavior (Fig. 3). At leaf level, reflectance near 550 and $700 \mathrm{~nm}$ are maximally sensitive to moderate to high chlorophyll content (Chappelle, Kim, \& McMurtrey, 1992; Gitelson \& Merzlyak 1994a, 1994b, 1996). In the wheat canopy, we found that reflectance in these spectral bands were much more sensitive to $\mathrm{VF}>60 \%$ than reflectance in the blue and the red (Fig. 2A).

Our findings for wheat canopy are consistent with Kanemasu (1974) who reported a decrease of the NIR reflectance for wheat, sorghum, and soybeans in the midseason. At that time, reflectance in the green (near $545 \mathrm{~nm}$ ) was greater than in the red (at $655 \mathrm{~nm}$ ), whereas early in the season the reverse was true. He suggested using the reflectance ratio $R_{545} / R_{655}$ as an indicator of crop maturity late in the season.

\subsection{Algorithms development}

The reflectance in the green (around $550 \mathrm{~nm}$ ), as well as near $700 \mathrm{~nm}$, and the red reflectance near $670 \mathrm{~nm}$, were used for estimating VF. When VF ranged from $0 \%$ to $60 \%$, the absolute difference between the two $\left(R_{\text {green }}-R_{\text {red }}\right)$ increased (not shown). This increase is caused by sharp decline of $R_{\text {red }}$, which is associated with chlorophyll absorption by crop during early-season growth, and a moderate 

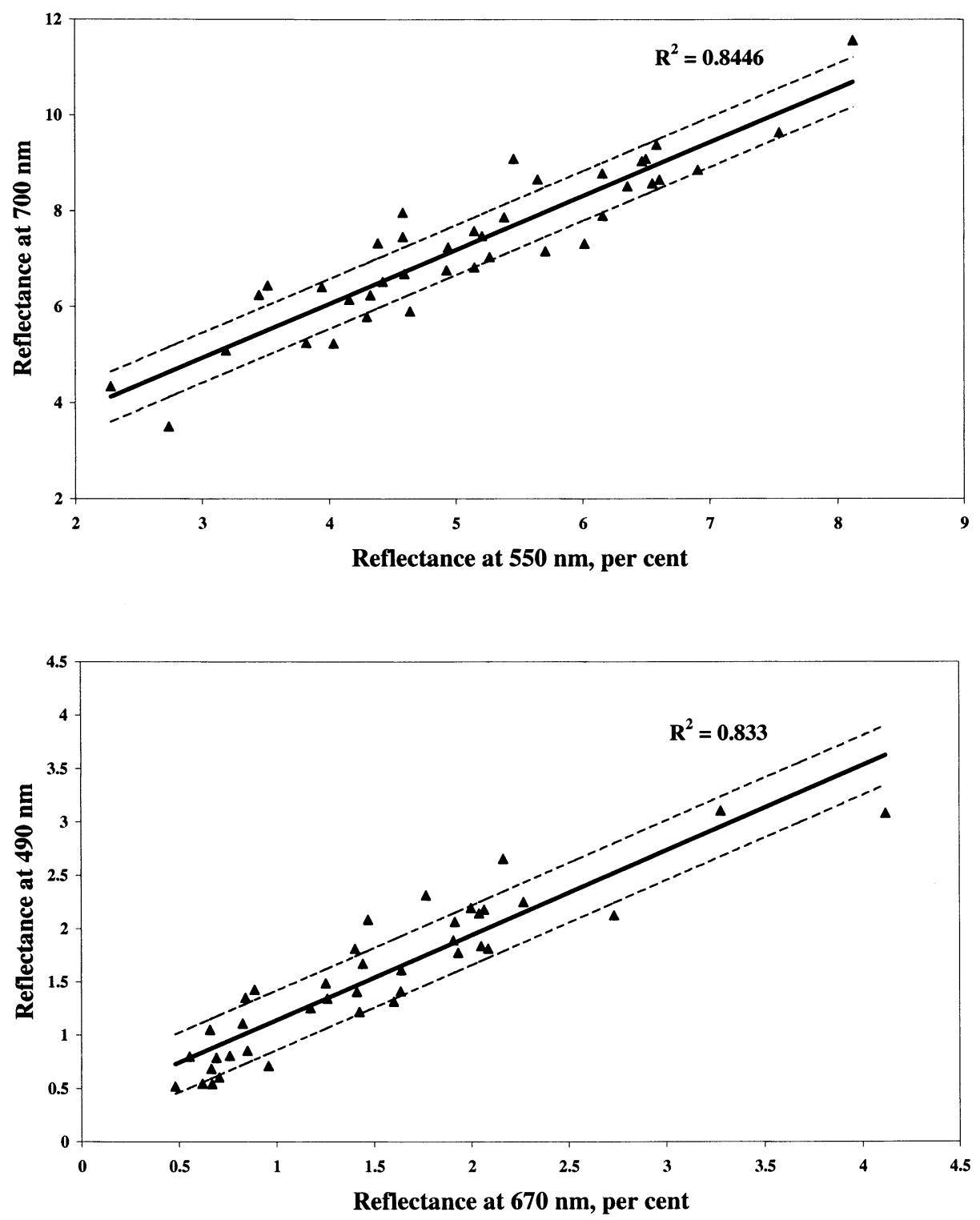

Fig. 3. Reflectance at $700 \mathrm{~nm}\left(R_{700}\right)$ versus reflectance at $550 \mathrm{~nm}\left(R_{550}\right)$ - $(\mathrm{A})$ and reflectance at $670 \mathrm{~nm}\left(R_{670}\right)$ versus $490 \mathrm{~nm}\left(R_{490}\right)$ - $(\mathrm{B})$ measured at 32 locations above a wheat canopy with VF between $60 \%$ and $100 \%$. Solid lines are best-fit functions. Thin lines show root-mean square deviation of sample points from the line of best fit. For $\mathrm{VF}>60 \%$, reflectances $R_{550}$ and $R_{700}$ as well as $R_{490}$ and $R_{670}$ were closely correlated. Thus, for $\mathrm{VF}>60 \%$, the band near $490 \mathrm{~nm}$ is identical in information content to that near $670 \mathrm{~nm}$, and band near $550 \mathrm{~nm}$ is identical to that near $700 \mathrm{~nm}$.

decrease of the $R_{\text {green }}$ (Fig. 2A). For VF $>60 \%$, the difference leveled off and then slightly decreased; it depended primarily on $R_{\text {green }}$, which decreased with an increase of $\mathrm{VF}$, while there was virtually no change in $R_{\text {red }}$ (Fig. 2A). The relationship between the sum $\left(R_{\text {green }}+R_{\text {red }}\right)$ and VF tends toward hyperbolic, and decreased significantly for VF $>60 \%$ (not shown). Thus, when VF ranged from $0 \%$ to $60 \%$, the difference $\left(R_{\text {green }}-R_{\text {red }}\right)$ increased substantially while the $\left(R_{\text {green }}+R_{\text {red }}\right)$ decreased; as a result, the ratio $\left(R_{\text {green }}-R_{\text {red }}\right) /\left(R_{\text {green }}+R_{\text {red }}\right)$ increased with an increase in VF. For VF $>60 \%$, the sum decreased due to a decrease of $R_{\text {green }}$, while $R_{\text {red }}$ remained almost invariant (Fig. 2A). As a result, the ratio $\left(R_{\text {green }}-R_{\text {red }}\right) /\left(R_{\text {green }}+R_{\text {red }}\right)$ did increase. Therefore, the normalization of the reflectance difference
( $\left.R_{\text {green }}-R_{\text {red }}\right)$ to the sum $\left(R_{\text {green }}+R_{\text {red }}\right)$ allowed us to obtain a quite linear relationship between the index and percent vegetation cover (Fig. 2B).

Thus, indices to estimate VF were constructed based on the difference of reflectances $\left(R_{\text {green }}-R_{\text {red }}\right)$ and $\left(R_{700}-R_{\text {red }}\right)$, normalized to their corresponding sums $\left(R_{\text {green }}+R_{\text {red }}\right)$ and $\left(R_{700}+R_{\text {red }}\right)$. We suggest the following indices for $\mathrm{VF}$ estimation (Fig. 2B):

$$
\begin{aligned}
& \mathrm{VI}_{\text {green }}=\left(R_{\text {green }}-R_{\text {red }}\right) /\left(R_{\text {green }}+R_{\text {red }}\right) \\
& \mathrm{VI}_{700}=\left(R_{700}-R_{\text {red }}\right) /\left(R_{700}-R_{\text {red }}\right)
\end{aligned}
$$

The behavior of the $R_{700}$ versus VF was the same as was the case for $R_{\text {green }}$. Thus, the relationship $\left(R_{700}-R_{\text {red }}\right) /$ 
$\left(R_{700}+R_{\text {red }}\right)$ vs. VF was almost the same as that of $\left(R_{\text {green }}-R_{\text {red }}\right) /\left(R_{\text {green }}+R_{\text {red }}\right)$. Both indices correlated closely with VF $\left(r^{2}>.91\right)$ with standard error of VF estimation not higher than $9.7 \%$.

\subsection{Visible Atmospherically Resistant Index (VARI)}

To reduce atmospheric effects, the concept of ARVI (Kaufman \& Tanre, 1992) has been used. Starting with the index (1) that is sensitive to VF (Fig. 2B), the effect of the atmosphere on the red and green is similar since both are adjacent in the spectrum. Although the green has a shorter wavelength, green reflectance is higher, so the two effects cancel each other. In the denominator (1), atmospheric effects exist in the green and red. ARVI assumed that the effect in the blue is twice as large as in the red, so to correct for the effect in the red and the green, we subtracted blue. Thus, index (1), was transformed to the following Visible $A$ tmospherically Resistant Index (VARI ${ }_{\text {green }}$ )

VARI $_{\text {green }}=\left(R_{\text {green }}-R_{\text {red }}\right) /\left(R_{\text {green }}+R_{\text {red }}-R_{\text {blue }}\right)$

The difference between the VI in Eq. (1) and VARI green in Eq. (3) was designed only to introduce an atmospheric self-correction. However, we found that coincidentally VARI was more sensitive to VF due to the introduction of the blue reflectance. For $\mathrm{VF}>50 \%, R_{\text {red }}$ was almost equal to $R_{\text {blue }}$ (Fig. $3 \mathrm{~b}$ ), while $R_{\text {green }}$ continued to decrease with increase in VF (Fig. 2a). Thus, VARI had a more linear relationship with VF than index $\left(R_{\text {green }}-R_{\text {red }}\right) /$ $\left(R_{\text {green }}+R_{\text {red }}\right)$, and was $32 \%$ more sensitive to VF.

We also corrected for some atmospheric effects at $700 \mathrm{~nm}$. In this case, in a similar way to ARVI (Kaufman \& Tanre, 1992) and Green Atmospherically Resistant Index

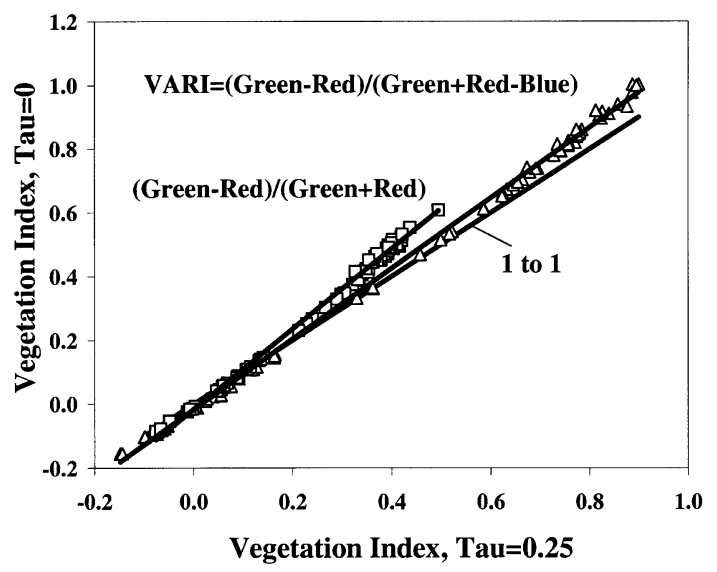

Fig. 4. Vegetation indices calculated for atmosphere with optical thickness $\tau=0$, plotted versus indices calculated for the atmosphere with $\tau=0.25$. The atmospheric effects manifest themselves as a distance from $1 \times 1$ line. For the index $\left(R_{\text {green }}-R_{\text {red }}\right) /\left(R_{\text {green }}+R_{\text {red }}\right)$ maximal variation from $1 \times 1$ line was more than $25 \%$, while for visible atmospherically resistant index VARI it was $<10 \%$.

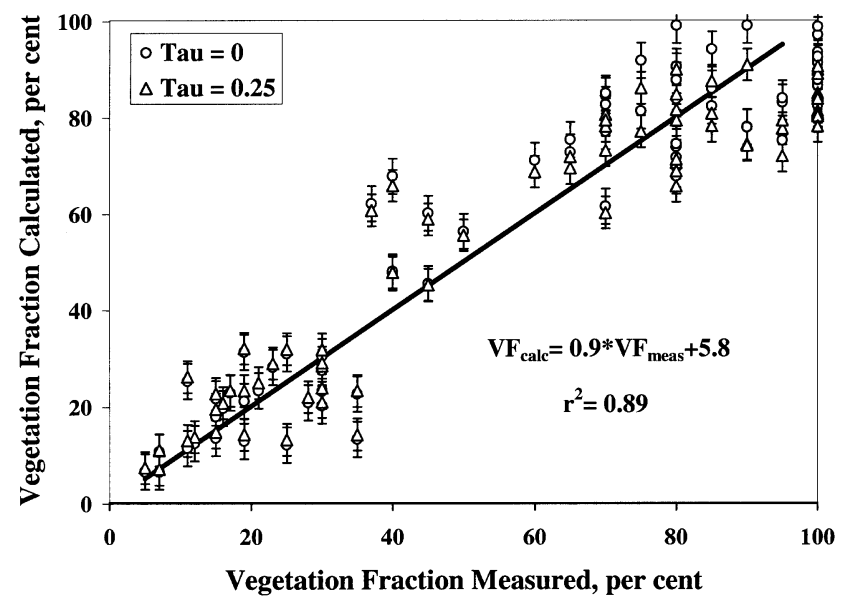

Fig. 5. VF calculated using visible atmospherically resistant index VARI versus VF retrieved from a digital image taken above the canopy for atmospheric optical thickness $\tau=0$ and $\tau=0.25$. The line $\mathrm{VF}_{\text {calc }}=\mathrm{VF}_{\text {meas }}$ is also provided for reference. The error of VF prediction was less than $9.4 \%$. Error bars are one standard deviation of calculated VF from actually measured values.

(GARI) (Gitelson, Kaufman, \& Merzlyak, 1996), we optimized the resistance of the index to the aerosol effects by introducing the coefficients for $R_{\text {red }}$ and $R_{\text {blue }}$. We allowed the coefficients of the red and blue channels to float and optimized them (by a minimalization scheme) so that the change in the index $\mathrm{VARI}_{700}$ with a change in optical thickness from 0 to 0.25 was minimal. This was similar to the process that generated ARVI and GARI in the first place, though here we used several aerosol models so the optimization was more rigorous. After optimization to minimize the atmospheric effects the index had a form

$$
\begin{aligned}
\text { VARI }_{700}= & \left(R_{700}-1.7 * R_{\text {red }}+0.7 * R_{\text {blue }}\right) \\
& /\left(R_{700}+2.3 * R_{\text {red }}-1.3 * R_{\text {blue }}\right)
\end{aligned}
$$

In both Eqs. (3) and (4), coefficients of determination $\left(r^{2}\right)$ for the relationships VARI vs. VF were higher than 0.95 and error of VF estimation was $<7 \%$.

The effect of atmospheric conditions on VF estimation by index $\left(R_{\text {green }}-R_{\text {red }}\right) /\left(R_{\text {green }}+R_{\text {red }}\right)$ and the $\mathrm{VARI}_{\text {green }}$ (Eq. (3)) was studied. As in Kaufman and Tanre (1992) and Gitelson et al. (1996), we used the radiative transfer code of Dave and Gazdag (1970) introduced the surface reflectance value for each wavelength and calculated the apparent reflectance at the top of the atmosphere once for optical thickness $\tau=0$ and second time for $\tau=0.25$. Then, the vegetation indices were calculated using the apparent reflectance at the top of atmosphere. In Fig. 4, we compared vegetation indices calculated for $\tau=0$ against vegetation indices calculated for $\tau=0.25$. In these coordinates, the atmospheric effects manifest themselves as a distance from the $1 \times 1$ line $\left(\mathrm{VI}_{\tau=0}=\mathrm{VI}_{\tau=0.25}\right)$. It can be seen that the atmosphere affected the VARI green minimally $(<10 \%)$, while the $\left(R_{\text {green }}-R_{\text {red }}\right) /\left(R_{\text {green }}+R_{\text {red }}\right)$ was affected to a much 


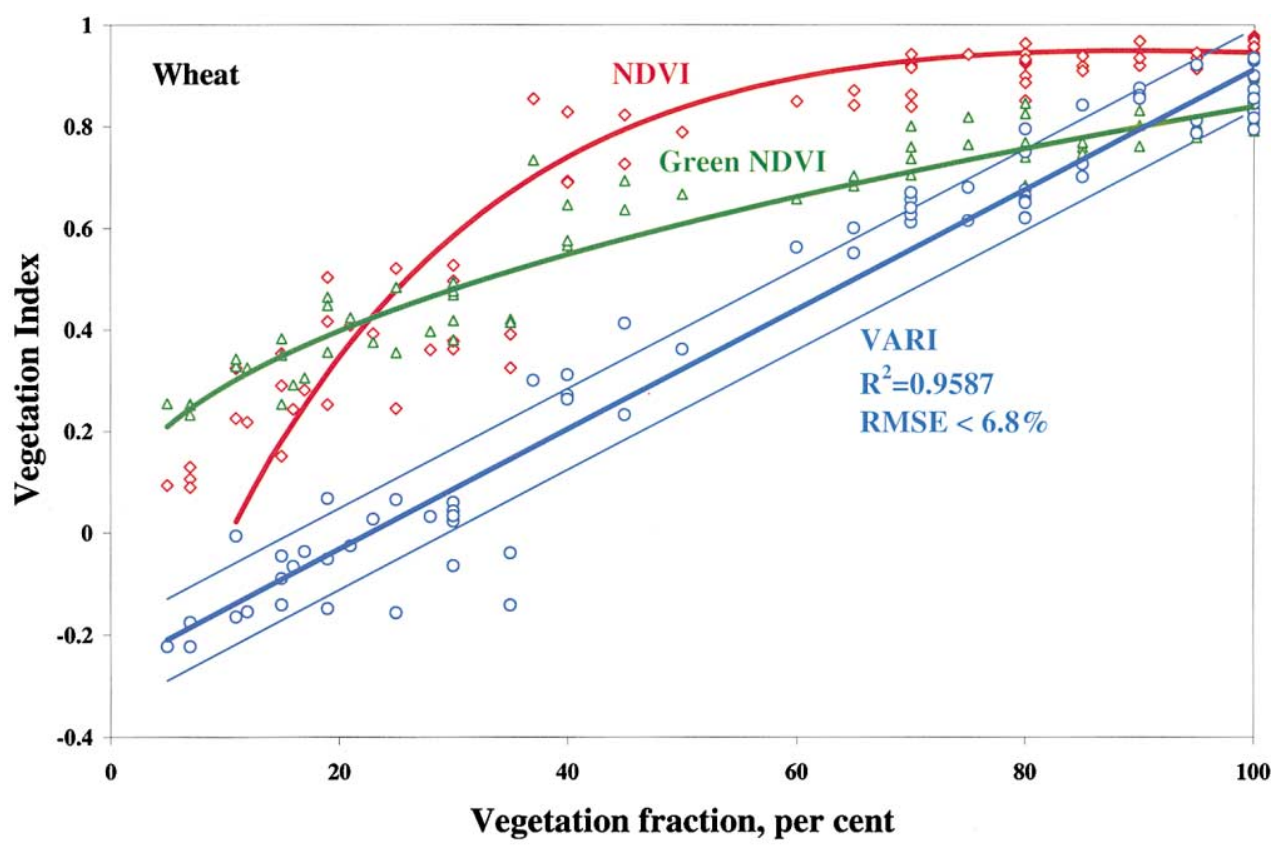

Fig. 6. Vegetation indices NDVI, Green NDVI, and VARI plotted versus wheat VF. In the range of VF from $0 \%$ to $50 \%$, NDVI was more sensitive to VF than VARI and Green NDVI. For VF $>50 \%$, Green NDVI was more sensitive to VF than of NDVI that leveled off and was virtually invariant. Index VARI remained sensitive to $\mathrm{VF}$ in whole range of $\mathrm{VF}$ from $0 \%$ to $100 \%$.

greater extent $(>25 \%)$. The comparison of VF measured and predicted by VARI green $_{\text {for }}$ two very different atmospheric conditions is shown in Fig. 5. Error of VF prediction was less than 9.4\%. Quantitatively, the same results (not shown) were obtained for the index VARI 700 (Eq. (4)).

The VARI $\mathrm{Vreen}_{\text {, }}$, the NDVI, and Green NDVI $=\left(R_{\mathrm{NIR}}-\right.$ $\left.R_{\text {green }}\right) /\left(R_{\mathrm{NIR}}+R_{\text {green }}\right)$ (Gitelson et al., 1996), simulated in MODIS spectral channels, were plotted versus VF for wheat (Fig. 6). For VF between $0 \%$ and $50 \%$, NDVI was maximally sensitive to VF. For VF $>60 \%$, NDVI leveled off and was virtually invariant and Green NDVI had little bit more sensitivity to VF. The VARI remained sensitive to VF in whole range of VF from $0 \%$ to $100 \%$. It seems worth noting that when the NIR reflectance is insensitive to moderate to high VF, as for wheat studied (Fig. 2A), the use of the green channel together with $\mathrm{R}_{\mathrm{NIR}}$ in Green NDVI provides only slightly more sensitivity to VF than of NDVI. In such a situation, VF could be estimated remotely solely by means of reflectance in visible range of the spectrum.

\subsection{Algorithms validation}

To test the above algorithms, the accuracy of VF prediction was determined. We employed the relationship VARI vs. VF obtained for a model development data set (wheat reflectance spectra and VF for 71 samples taken in 1998-1999 growing season):

$\mathrm{VF}, \%=84.75 * \mathrm{VARI}_{\text {green }}+22.78$

Reflectances in MODIS spectral channels for model validation data set (four wheat species, 41 samples, obtained in 1997-1998 growing season) were used to calculate VARI. Then, the predicted VF was compared with VF retrieved from digital images. The predicted and measured VF for these 41 observations were in very favorable agreement (determination coefficient $r^{2}>.91$ ), with a nearly $1: 1$ correspondence in the paired values. The same procedure was used to validate index VARI $\operatorname{VAO}_{700}=\left(R_{700}-1.7 R_{\text {red }}+0.7 R_{\text {blue }}\right) /$ $\left(R_{700}+2.3 R_{\text {red }}-1.3 R_{\text {blue }}\right)$. Reflectances in MERIS spectral channels were used to calculate the index. For both predictors, the standard error for VF prediction was $<10 \%$.

Developed algorithms were also tested by means of three independent data sets obtained over cornfields in Nebraska. Fig. 7A shows the sum and difference of green and red reflectances against VF. During corn growth, the difference increased consistently because the red reflectance showed decline, even for high VF. It is different from wheat with much higher density (maximal LAI $=12$, Fig. 2A), where red reflectance was virtually invariant in respect to VF $>60 \%$. Comparison of NDVI, Green NDVI and VARI (Fig. 7B) shows that for VF exceeding 55\%, both NDVI and Green NDVI lost some sensitivity to VF, whereas the relationship VARI versus VF resulted in a steep slope.

To compare quantitatively the sensitivity of NDVI, GARI (Gitelson et al., 1996), and VARI to VF exceeding $50 \%$, several estimates were used. Firstly, slopes of the relationships VF versus indices were calculated (Table 1, and Fig. 8A and B). It can be seen that for all data sets the slope was minimal for NDVI, and maximal in VARI. Quantitatively the same results were obtained for index $\operatorname{VARI}_{700}=\left(R_{700}-1.7 R_{\text {red }}+0.7 R_{\text {blue }}\right) /$ 

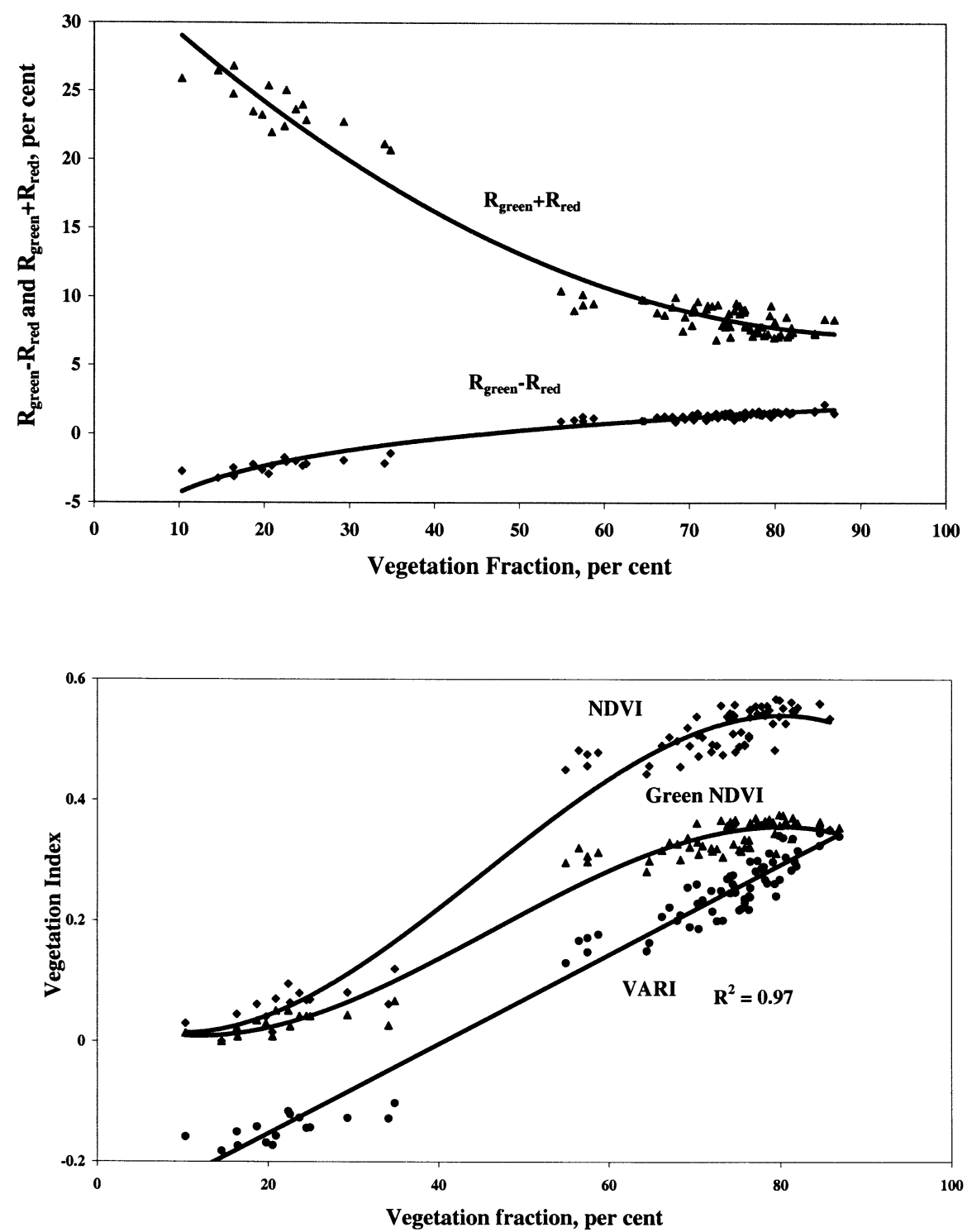

Fig. 7. (A) Difference and sum of corn green and red reflectance versus VF. During corn growth, the difference increased and the sum decreased consistently due to red reflectance showed a steep decline even for high VF. (B) Vegetation indices NDVI, Green NDVI and VARI plotted versus corn VF. For VF exceeded $55 \%$, sensitivity of NDVI and Green NDVI to VF decreased substantially, while the VARI remained sensitive to VF.

$\left(R_{700}+2.3 R_{\text {red }}-1.3 R_{\text {blue }}\right)$. Another estimate was based on the ratio of the slope to standard deviation of slope (Table 2). A third estimate was based on the ratio

Table 1

Sensitivity of indices to VF, expressed as a slope of relationship "index versus VF"

\begin{tabular}{llllll}
\hline & Wheat & Wheat & Corn & Corn & Corn \\
Index & $1997-1998$ & $1998-1999$ & $1998 \mathrm{~A}$ & $1998 \mathrm{~B}$ & 1999 \\
\hline NDVI & 24 & 27 & 24 & 36 & 33 \\
GARI & 32 & 34 & 47 & 24 & 34 \\
VARI & 80 & 86 & 72 & 67 & 68 \\
\hline
\end{tabular}

VF ranged from $50 \%$ to $100 \%$.

Slope in $10^{2 *}(\%)^{-1}$
$\left(\mathrm{VI}_{100}-\mathrm{VI}_{50}\right) /\left(\mathrm{STD}_{100}\right)$, where $\left(\mathrm{VI}_{100}-\mathrm{VI}_{50}\right)$ is the difference between indices for $\mathrm{VF}=100 \%$ and $\mathrm{VF}=50 \%$, respectively, and $\mathrm{STD}_{100}$ is the standard deviation of the index for $\mathrm{VF}=100 \%$ (Table 3). All estimates showed that the developed indices were at least two-fold more sensitive to $\mathrm{VF}$ for different vegetation types and more efficient than NDVI in estimating VF exceeded $50 \%$. These indices will complement the widely used NDVI, ARVI, Soil Adjusted Vegetation Index (SAVI) and others, which are based on the red and the NIR bands in VF estimation, and also Green NDVI and GARI those are based on the green and the NIR bands.

It should be noted that for corn with LAI ranged from 2.5 in 1998 to 3.4 in 1999, index values and the slopes of "VARI versus VF" relationships were only slightly differ- 

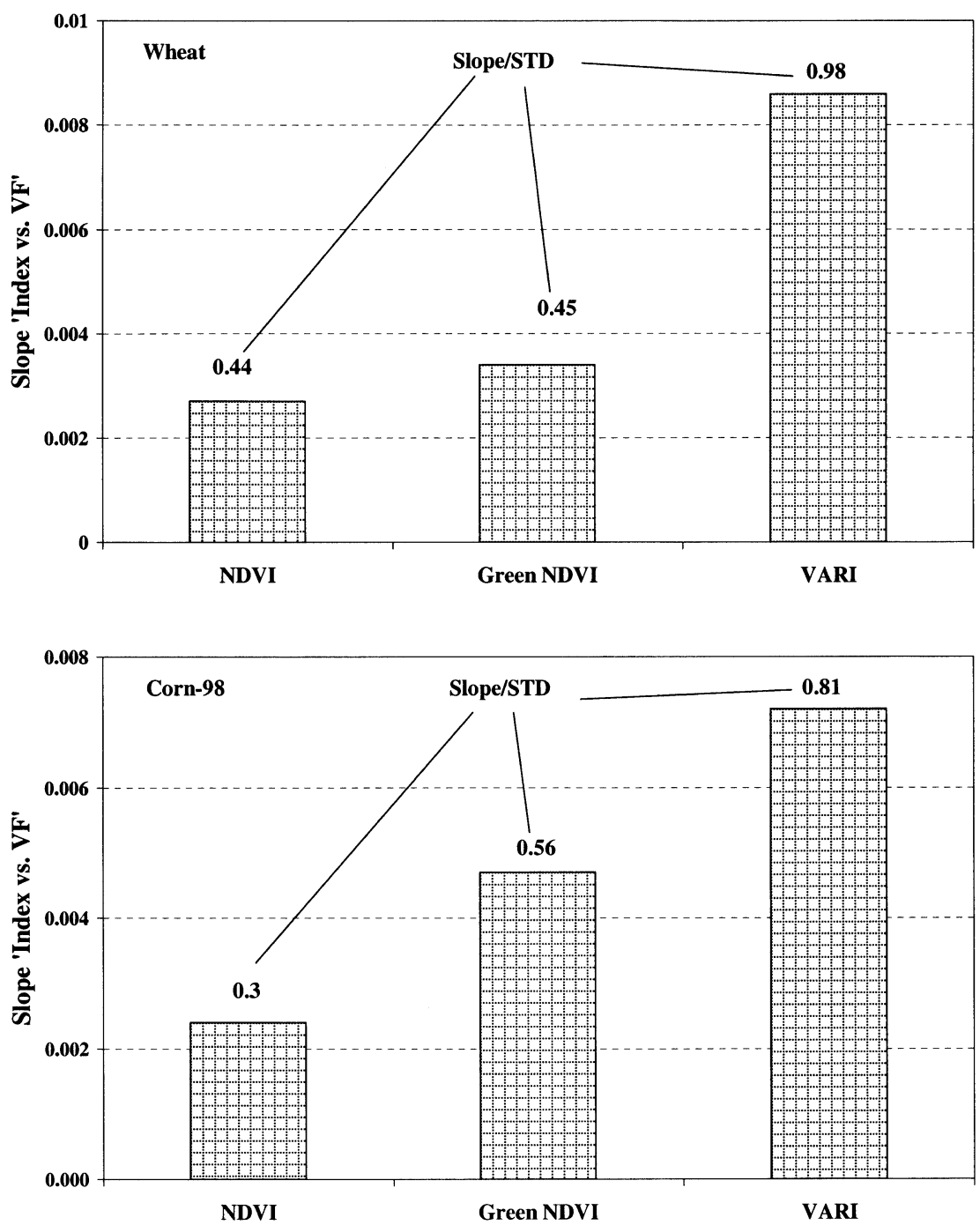

Fig. 8. Sensitivity of indices to VF, expressed as a slope of relationship "index versus VF" for wheat (A) and corn (B). VF ranged from $50 \%$ to $100 \%$. The values of slope normalized to standard deviation of the slope also shown. For $\mathrm{VF}>50 \%$, the slope of the relationship VARI versus VF was at least two times higher than of NDVI versus VF.

ent (varied from 67 to 72 , Table 1). The same took place for four wheat species with little variable LAI (slopes varied from 80 to 86 , Table 1). However, slope of the relationship "VARI versus VF" for wheat (Fig. 6) was $10-15 \%$ higher than for corn (Fig. 7B). Thus, for crops with very large difference in LAI (LAI was more than 12 in wheat and 3.5 at most in corn), LAI was a factor that

Table 2

Slope of the relationship "index versus VF" normalized to standard deviation of the slope

\begin{tabular}{llllll}
\hline & Wheat & Wheat & Corn & Corn & Corn \\
Index & $1997-1998$ & $1998-1999$ & $1998 \mathrm{~A}$ & $1998 \mathrm{~B}$ & 1999 \\
\hline NDVI & 0.4 & 0.44 & 0.3 & 0.22 & 0.27 \\
GARI & 0.49 & 0.45 & 0.56 & 0.23 & 0.32 \\
VARI & 0.91 & 0.98 & 0.81 & 0.4 & 0.53 \\
\hline
\end{tabular}

VF ranged from $50 \%$ to $100 \%$. also affected indices. For wheat with much higher LAI, the red and the green reflectances were smaller than for corn; thus, the sum of the red and the green (as well as $700 \mathrm{~nm}$ ) reflectance was lower with the result being an increase of indices for wheat. Taking into account that we investigated crops with extremely different LAI, one can conclude that $10-15 \%$ difference in slope "VARI vs. VF" is, probably, maximal expected error in VF estimation when LAI vary

Table 3

Sensitivity of indices to VF expressed as $\left(\mathrm{VI}_{100}-\mathrm{VI}_{50}\right) / \mathrm{STD}_{100}$, where $\mathrm{VI}_{100}$ and $\mathrm{VI}_{50}$ are vegetation indices for $\mathrm{VF} 100 \%$ and $50 \%$, respectively; $\mathrm{STD}_{100}$ is standard deviation of the index with VF of $100 \%$

\begin{tabular}{lll}
\hline Index & Wheat $1997-1998$ & Wheat 1998-1999 \\
\hline NDVI & 24 & 27 \\
GARI & 32 & 34 \\
VARI & 80 & 86
\end{tabular}


very widely. Further research is under way to investigate the sensitivity of the indices to LAI.

\section{Conclusions}

In studied wheat and corn, NIR reflectance leveled off or even decreased with an increase of VF at or near the midseason. It can be a limiting factor in the use of that spectral region for VF estimating. In this study, the information content inherent in wheat and corn reflectance spectra was evaluated. When VF was less than $60 \%$, from emergence till middle of the elongation stage, four distinct, and quite independent, spectral bands of reflectance in visible range existed: $400-500 \mathrm{~nm} ; 530-600 \mathrm{~nm}$, near $670 \mathrm{~nm}$, and around $700 \mathrm{~nm}$. When $\mathrm{VF}>60 \%$, the information content was focused on only two independent pairs of spectral bands: (a) 400-500 nm and near $670 \mathrm{~nm}$; and (b) around $550 \mathrm{~nm}$ and near $700 \mathrm{~nm}$.

Contrast between the green (or a 700-nm band) and the red (near $670 \mathrm{~nm}$ ) reflectances was used in developed indices, which were nearly linearly proportional to wheat and corn VF ranged from 0 to $100 \%$. Atmospherically resistant indices based on reflectances in the blue (around $470-490 \mathrm{~nm})$ and red $(660-680 \mathrm{~nm})$ and either the green (near $550 \mathrm{~nm}$ ) or the red edge (near $700 \mathrm{~nm}$ ) ranges seem more robust in estimating VF of wheat and corn than the $\mathrm{red} / \mathrm{NIR}$ indices commonly used. The indices were validated by independent data sets for four wheat species in Israel and for corn in Nebraska.

Thus, we propose to use only the visible range of the spectrum to estimate quantitatively VF, and link our findings to new satellite technologies and the high spectral and radiometric resolutions achieved in the recently launched SeaWiFS, MODIS, ASTER, MISR, and in the near future MERIS system.

The spectral features of wheat and corn reflectance revealed in this study would conceivably be comparable with other vegetation types. It should be stressed however, that the applicability of the proposed techniques to other vegetation types must yet be verified. Reflectance from green vegetated surfaces in the visible region of the spectrum is often quite low and the differences in levels of reflectivity among the visible channels is much smaller than between the red and NIR. Despite the subtle differences in response from vegetation in the visible range, the sensitivity of our newly suggested indices to moderate to high VF is much greater than for the NDVI. Our recently obtained results of VF estimation using data taken by aircraftmounted sensors as ADAR, CASI, and HyMap over agricultural fields and orchards showed that the proposed indices were both accurate and useful. Nevertheless, we recognize that differences in species, illumination, canopy architecture, soil properties and many other factors may potentially decrease the accuracy of the developed indexes. In order to devise comprehensive algorithms for remote monitoring of $\mathrm{VF}$, additional research dealing with the sensitivity of the newly suggested indices to these external factors is required.

\section{Acknowledgments}

The authors are very grateful for assistance provided by Uri Grits, Galina Keydan, Yoav Zur, Ben-Gurion University of the Negev, Israel, and for the data and assistance provided by David Derry and Juan Ramirez, the University of Nebraska-Lincoln, USA. We are also thanking anonymous reviewer for valuable suggestions and criticism.

\section{References}

Allen, W. A., \& Richardson, A. J. (1968). Interaction of light with plant canopy. Journal of the Optical Society of America, 58 (8), 1023-1028.

Aoki, M., Yabuki, K., Totsuka, T., \& Nishida, M. (1986). Remote sensing of chlorophyll content of leaf: I. Effective spectral reflection characteristics of leaf for evaluation of chlorophyll content in leaves of dicotyledons. Environmental Control in Biology, 24 (1), 21-26.

Asrar, G., Fuchs, M., Kanemasu, E. T., \& Hatfield, J. L. (1984). Estimating absorbed photosynthetic radiation and leaf area index from spectral reflectance in wheat. Agronomy Journal, 76, 300-306.

Baret, F., Guyot, G., \& Major, D. (1989). TSAVI: a vegetation index which minimizes soil brightness effects on LAI and APAR estimation. In: 12th Canadian Symp. on Remote Sensing and IGARSS'90, Vancouver, Canada, 10-14 July 1989. (pp. 1-4).

Baret, F., Jacquemoud, S., \& Hanocq, J. F. (1993). The soil line concept in remote sensing. Remote Sensing Reviews, 7, 65-82.

Buschmann, C., \& Nagel, E. (1993). In vivo spectroscopy and internal optics of leaves as basis for remote sensing of vegetation. International Journal of Remote Sensing, 14, 711-722.

Chappelle, E. W., Kim, M. S., \& McMurtrey, J. E. III (1992). Ratio analysis of reflectance spectra (RARS): an algorithm for the remote estimation of the concentrations of chlorophyll $a$, chlorophyll $b$, and carotenoids in soybean leaves. Remote Sensing of Environment, 39, 239-247.

Colwell, J. E. (1974). Vegetation canopy reflectance. Remote Sensing of Environment, 3, 175-183.

Daughtry, C. S. T., Bauer, M. E., Crecelius, D. W., \& Hixson, M. M. (1980). Effects of management practices on reflectance of spring wheat canopies. Agronomy Journal, 72, 1055-1060.

Dave, J. V., \& Gazdag, J. (1970). A modified Fourier transform method for multiple scattering calculations in a plane parallel Mie atmosphere. Applied Optics, 9, 1457-1466.

Fernandez, S., Vidal, D., Simon, E., \& Sole-Sugranes, L. (1994). Radiometric characteristics of triticum aestivum $\mathrm{cv}$. astral under water and nitrogen stress. International Journal of Remote Sensing, 15, 1867-1884.

Gitelson, A., Kaufman, Y., \& Merzlyak, M. (1996). Use of a green channel in remote sensing of global vegetation from EOS-MODIS. Remote Sensing of Environment, 58, 289-298.

Gitelson, A., \& Merzlyak, M. (1997). Remote estimation of chlorophyll content in higher plant leaves. International Journal of Remote Sensing, $18,291-298$.

Gitelson, A., \& Merzlyak, M. N. (1994a). Quantitative estimation of chlorophyll using reflectance spectra: experiments with autumn chestnut and maple leaves. Journal of Photochemistry and Photobiology (B), 22, $247-252$

Gitelson, A., \& Merzlyak, M. N. (1996). Signature analysis of leaf reflectance spectra: algorithm development for remote sensing of chlorophyll. Journal of Plant Physiology, 148, 494-500. 
Gitelson, A. A., \& Merzlyak, M. (1994b). Spectral reflectance changes associated with autumn senescence of Asculus hippocastanum and Acer platanoides leaves. Spectral features and relation to chlorophyll estimation. Journal of Plant Physiology, 143, 286-292.

Gobron, N., Pinty, B., Verstraete, M., \& Govaerts, Y. (1999). The MERIS global vegetation index (MGVI): description and preliminary application. International Journal of Remote Sensing, 20, 1917-1927.

Holben, B. N. (1986). Characteristics of maximum value composite images for temporal AVHRR data. International Journal of Remote Sensing, 7, $1417-1437$.

Huete, A. R. (1988). A soil-adjusted vegetation index (SAVI). Remote Sensing of Environment, 25, 295-309.

Huete, A. R., Jackson, R. D., \& Post, D. F. (1985). Spectral response of plant canopy with different soil background. Remote Sensing of Environment, 17, 37-53.

Jackson, R. D., Clarke, T. R., \& Moran, M. S. (1992). Bidirectional calibration results for 11 spectralon and $16 \mathrm{BaSO}_{4}$ reference reflectance panels. Remote Sensing of Environment, 40, 231-239.

Jackson, R. D., \& Ezra, C. E. (1985). Spectral response of cotton to suddenly induced water stress. International Journal of Remote Sensing, 6 , $177-185$.

Jackson, R. D., \& Pinter, P. J. Jr. (1986). Spectral response of architecturally different wheat canopies. Remote Sensing of Environment, 20, 43-56.

Jackson, R. D., Slater, P. N., \& Pinter, P. J. Jr. (1983). Discrimination of growth and water stress in wheat by various vegetation indices through clear and turbid atmosphere. Remote Sensing of Environment, 13, $187-208$.

Kanemasu, E. T. (1974). Seasonal canopy reflectance patterns of wheat, sorghum, and soybean. Remote Sensing of Environment, 3, 43-47.

Kaufman, Y. J. (1989). The atmospheric effect on remote sensing and its corrections. In: G. Asrar (Ed.), Theory and application of optical remote sensing (pp. 336-428). New York: Wiley.

Kaufman, Y. J., \& Tanre, D. (1992). Atmospherically resistant vegetation index (ARVI) for EOS-MODIS. IEEE Transactions on Geoscience and Remote Sensing, 30, 261-270.

Leamer, R. W., Noriega, J. R., \& Gerbermann, A. H. (1980). Reflectance of wheat cultivars as related to physiological growth stages. Agronomy Journal, 72, 1029-1032.

Leamer, R. W., Noriega, J. R., \& Wiegand, C. L. (1978). Seasonal changes in reflectance of two wheat cultivars. Agronomy Journal, 70, 113-118.

Myneni, R. B., Hall, F. G., Sellers, P. S., \& Marshak, A. L. (1995). The interpretation of spectral vegetation indexes. IEEE Transactions on Geoscience and Remote Sensing, 33, 481-486.

Myneni, R. B., Keeling, C. D., Tucker, C. J., Asrar, G., \& Nemani, R. R. (1997a). Increased plant growth in the northern high latitudes from 1981 to 1991 . Nature, $386,698-702$.

Muneni, R. B., Nemani, R. R., \& Running, S. W. (1997b). Estimation of global leaf area index and absorbed par using radiative transfer models. IEEE Transactions on Geoscience and Remote Sensing, 35, $1380-1393$.

Purevdorj, T., Tateishi, R., Ishiyama, T., \& Honda, Y. (1998). Relationships between percent vegetation cover and vegetation indices. International Journal of Remote Sensing, 19, 3519-3535.

Rouse, J. W., Haas, Jr., R. H., Schell, J. A., Deering, D. W. (1974). Monitoring vegetation systems in the Great Plains with ERTS, NASA SP-351. Third ERTS-1 Symposium, Vol. 1, pp. 309-317, NASA, Washington, DC.

Sellers, P. J. (1985). Canopy reflectance, photosynthesis and transpiration. International Journal of Remote Sensing, 6, 1335-1372.

Sellers, P. J. (1987). Canopy reflectance, photosynthesis and transpiration: II. The role of biophysics in the linearity of their interdependence. Remote Sensing of Environment, 21, 143-183.

Stark, R., \& Gitelson, A. (1999). Light distribution in field communities of irrigated wheat plants. In: Proceedings of the fourth international airborne remote sensing conference and exhibition/21st Canadian symposium on remote sensing, Ottawa, Ontario, Canada, 21-24 June 1999. (pp. 321-326).

Stark, R., \& Gitelson, A. (2000). Radiation regime in irrigated wheat. In: Proceedings of the second international on geospatial information in agriculture and forestry conference, Lake Buena Vista, Florida, 10-12 January 2000. (pp. II-89-II-96).

Suits, G. H. (1972). The calculation of the directional reflectance of vegetative canopy. Remote Sensing of Environment, 2, 117-125.

Tucker, C. J., Holben, B. N., Elgin, J. H. Jr., \& McMurtrey, J. E. III (1981). Remote sensing of total dry-matter accumulation in winter wheat. Remote Sensing of Environment, 11, 171-189.

Tucker, J. C. (1979). Red and photographic infrared linear combination for monitoring vegetation. Remote Sensing of Environment, 8, 127-150.

Tucker, J. C., Fung, I. Y., Keeling, C. D., \& Gammon, R. H. (1986). The relationships between atmospheric $\mathrm{CO}_{2}$ variations and satellite-derived vegetation index. Nature, 319, 195-199.

White, M. A., Asner, G. P., Nemani, R. R., Privette, J. L., \& Running, S. W. (2000). Measuring fractional cover and leaf area index in arid ecosystems. Digital camera, radiation transmittance, and laser altimetry methods. Remote Sensing of Environment, 74, 45-57.

Woebbecke, D. M., Meyer, G. E., Von Bargen, K., \& Mortensen, D. A. (1995). Color indices for weed identification under various soil residue and lighting conditions. Transactions of the ASAE, 38 (1), 259-269. 